\title{
Analisis Rasio Kinerja Keuangan Pada PT. Bank SULUTGO
}

\author{
Scarlet. E. Rawung \\ Joula. J. Rogahang \\ Joanne V. Mangindaan \\ Jurusan Ilmu Administrasi, Program Studi Administrasi Bisnis \\ Fakultas Ilmu Sosial dan Politik, Universitas Sam Ratulangi \\ rawung.scarlet07@gmail.com
}

\begin{abstract}
Research on using to find out and analyze financial performance at PT Bank-PLACES to GO. In this current era increasingly many companies appear and also being so tight, so from that company (bank) earnings should improve in order to be able to compete. The focus in this study is on the financial statements of the year 2015, 2016, and 2017, with financial ratios i.e. ratio of profitability, liquidity ratios, and ratios of the banking capital. While the source of the data used in this research is secondary data in the form of banking financial reports document from the year 2015 to 2017 are on acquire from webside https://www.banksulutgo.co.id. Results of the study showed a ratio of profitability have good financial kenerja, capital ratio and likuditas ratio also has a good financial performance, though in year 2015 to 2017 rising and decline but the financial performance the bank achieve not FLAMMABLE under standard BI BI standards but so can still in good financial ratio tells me. Therefore, PT. Bank SULUTGO should further improve the financial performance of a maximum in the next year.
\end{abstract}

Keywords: financial statements, Ratios, profitability Ratios, the ratio of capital likuditas

\section{Pendahuluan}

Bank merupakan lembaga yang menjalankan fungsi intermediasi, dalam perkembanngan sekanjutnya bank tidak hanya menjalankan fungsi intermediasi tetapi juga memberikan jasa dalam pelayanan lain kepada masyarakat, misalnya dalam lalu lintas pembayaran maupun jasa keuangan lainnya, sebagai lembaga kepercayaan bank tidak hanya di butuhkan atau bermanfaat bagi individuan masyarakat secara keseluruhan tetapi juga sangat berperan dalam pertumbuhan dan perkembangan ekonomi suatu negara dalam. Dalam proses intermediasi, dana yang dikerahkan atau mobilisasi oleh suatu bank selanjutnya akan di salurkan dan di investasikan ke sektor sekt Penilaian kinerja keuangan merupakan sumber informasi penting, karena akan menunjukan hasil operasi keuangan dan posisi keuangan yang telah dicapai. Oleh sebab itu perbankan harus menyajikan laporan keuangan lengkap dan benar, wajib untuk 
memperlihatkan kinerja keuangannya setiap periode, serta dapat di pertanggung jawabkan keakuratannya.

Dalam kesehariannya, Bank harus selalu memperhatikan kinerja keuangannya. Salah satu faktor yang dapat menunjukan bagaimana kinerja keuangan bank itu baik atau tidak yaitu dengan dengan melakukan analisis laporan keuangannya. Hal ini dilakukan karena dengan laporan keuangan dapat di nilai kinerja perubahan perbankan tersebut dan para pengguna jasa bank dapat menilai baik tidaknya kinerja keuangannya yang selanjutnya jika kinerjanya baik,maka dapat menarik minat para pengguna jasa bank,seperti : kreditur, investor, pengusaha serta masyarakat pada umumnya. Laporan keuangan bank dapat di jadikan ukuran kinerja suatu bank dengan melakukan analisis laporan keuangan. Analisis rasio keuangan merupakan teknik analisis yang sering di pakai,karena merupakan teknik yang paling cepat untuk mengetahui kinerja keuangan bank.

Dengan adanya analisis kinerja keuangan ini, bisa membatu kita dalam menilai dan mengetahui kinerja bank dengan menggunakan rasio rasio bank antara lain ( Rasio solvabilitas, rasio likuiditas, rasio permodalan). Rasio solvabilitas adalah digunakan untuk mengukur tingkat pengelolahan sumber dana perusahaan, rasio likuiditas adalah rasio yang di gunakan untuk mengukur kemampuan perusahaan dalam menjamin kewajiban kewajiban lancarnya, rasio permodalan adalah rasio yang di gunakan untuk mengukur kemampuan perusahaan dalam menghasilkan keuntungan bagi perusahaan. Ketiga rasio ini memiliki hubungan erat dengan kinerja suatu perusahaan.

Dilihat dari laporan keuangan pada PT. Bank SULUTGO. Ditahun 2015, keuntungan atau laba yang di peroleh perusahaan pada akhir semester pertama menurun $11,75 \%$ di bandingkan periode yang sama pada tahun sebelumnya penurunan laba bersih terjadi diakibatkan kenaikan beban non bunga. Kemudian pada tahun 2016 berdasarkan laporan keuangan yang di publikasikan laba bersih PT Bank SULUT lebih meningkat 36,79\% dibanding tahun 2015, Sedangkan sepanjang 6 bulan tahun pertama tahun 2017 Bank SULUTGO mengalami peningkatan $11,01 \%$ dibandingkan posisi yang sama pada tahun sebelumnya. Dari uraian di atas kita bisa melihat naik turunnya kinerja keuangan pada Bank SULUTGO dalam perbandingan 3 tahun yaitu pada tahun 2015 sampai 2017.

Berdasarkan uraian di atas, maka menjadi inti permasalahan dapat di rumuskan sebagai berikut: 'Bagaimana kinerja keuangan PT. Bank SULUTGO 
ditinjau berdasarkan rasio profitabilitas, rasio likuditas dan rasio permodalan untuk periode 2015 sampai 2017? Sedangkan tujuan yang ingin dicapai dalam peneliian ini adalah untuk menilai Kinerja Keuangan PT. Bank SULUTGO ditinjau berdasarkan rasio profitabilitas, rasio likuditas dan rasio permodalan untuk periode 2015 sampai 2017.

\section{Fungsi Bank}

Perbankan Indonesia bertujuan menunjang pelaksanaan pembangunan nasional dalam rangka meningkatkan pemerataan,pertumbuhan ekonomi dan stabilitas nasional ke arah peningkatan kesejahteraan rakyat banyak, hal tersebut di tegaskan dalam pasal 4 Undang undang nomor 10 tahun 1998 tentang perubahan Undang undang no 7 tahun 1992 tentang perbankan pasal 3 salah satu fungsi bank adalah menyalurkan kredit baik kepada perorangan maupun badan usaha.Pemerintah sangat mendorong, mendukung dan membantu kepada sector UKM (Usaha Kecil Menengah) maupun yang lainnya. Keberadaan bank harus bermanfaat dan harus dapat dirasakan langsung oleh siapa saja baik oleh deposan maupun debitur,pelaku bisnis,karyawan.

Bagi pelaku bisnis atau pengusaha, bank merupakan media peputaran lalu lintas uang. Dan tempat dimana permasalahan keuangan dapat di selesaikan,baik melalui produk produk bank maupun jasa bank yang di tawarkan kepada nasabahnya, Semakin sempurna produk dan jasa yang di berikan bank kepada nasabahnya, tentunya akan memperlancar kegiatan bisnis nasabah serta lebih leluasa untuk bertransaksi di bank tersebut.

\section{Laporan Keuangan}

Laporan keuangan merupakam pokok atau hasil akhir dari suatu proses akuntasi yang menjadi bahan informasi bagi para pemakaiannya sebagai salah satu bahan dalam proses pengambilan keputusan dan juga dapat menggambarkan indikator kesusesan suatu perusahaan untuk mencapai tujuannyan (Harahap, 2010)

\section{Tujuan Laporan keuangan}

Laporan keuangan merupakan pertanggung jawaban manajemen atas sumber daya yang di percayakan untuk menambah suatu informasi yang ada dalam suatu laporan keuangan kepada para pemakai laporan keuangan supaya bisa membantu mereka dalam membuat keputusan ekonomi,dimana dalam menganalisis laporan keuangan sebenarnya mempunyai tujuan yang bermacam-macam. 


\section{Rasio Profitabilitas}

(Galagher, 2011) rasio profitabilitas adalah rasio yang menggambarkan tentang seberapa besar pendapatan perusahaan dibandingkan dengan pengeluarannnya, seberapa besar kemampuan perusahaan untuk menghasilkan laba dalam hubungannya dengan penjualan,aktiva dan modal.

\section{Rasio Likuiditas}

Rasio likuiditas merupakan suatu indikator mengenai kemampuan perusahaan perusahaan membayar semua kewajiban finansial jangka pendek pada saat jatuh tempo dengan menggunakan aktiva lancar yang tersedia.

\section{Rasio Permodalan}

Analisa permodalan bank atau secara teknis disebut juga Analysis of Bank Capital ini akan membahas secara bertahap tentang fungsi dari Bank Capital, cara pengukuran kebutuhan modal dan cara perhitungan ratio dari solvabilitas suatu bank (Muljono, 2011)

\section{Metode Penelitian}

Penelitian ini di lakukan pada kantor PT. Bank Pembangunan Daerah Sulawesi Utara Gorontalo (BANK SULUTGO) yang beralamat cabang pusat yang terletak di Jl.Samratulangi No. 9 Manado dan library rearch guna mendapatkan tambahan informasi lainnya melalui akses internet ke website PT. Bank Pembangunan Daerah Sulawesi Utara Gorontalo (BANK SULUTGO)

https://www.banksulutgo.co.id dan link lainnya yang relevan. Jenis Penelitian : Adapun yang menjadi metode penelitian ini bersifat analisis deskriptif kuantitatif dengan pendekatan rasio-rasio keuangan bank dalam kajian : rasio profitabilitas, rasio likuiditas, dan rasio permodalan

\section{Teknik Analisis Data}

\section{Ratio Profitabilitas}

Ratio Profitabilitas yaitu digunakan untuk mengukur kemampuan perusahaan atau perbankan dalam memperoleh laba atau keuntungan profitabilitas suatu perbankan mewujudkan perbandingan antara laba dengan aktiva atau modal yang menghasilkan laba tersebut. Yang termaksud dalam rasio ini.

1. Return On Asset (ROA) :

Laba bersih setelah pajak

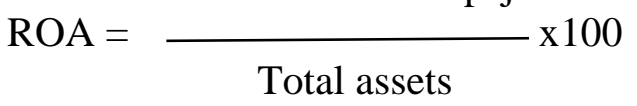

2. Return on Equity (ROE) :

Laba bersih setelah pajak

$$
\mathrm{ROE}=\frac{}{\text { Total Ekuitas }} \times 100
$$


3. Net Profit Margin

Laba Bersih setelah pajak

$\mathrm{NPM}=$

Pendapatan Operasional

\section{Ratio Likuiditas}

Ratio likuiditas yaitu menggambarkan kemampuan perusahaan untuk menyelesaikan kewajiban jangka pendeknya, rasio rasio ini dapat di hitung melalui sumber tentang modal kerja yaitu pos pos aktiva lancar dan hutang lancar . Rasio rasio yang dapat di gunakan untuk mengukur likuiditas perbankan yaitu rasio lancar,rasio cepat dan rasio kas.

1. Loan to assets ratio :

$$
\mathrm{LAR}=\frac{\text { Total Loan }}{\text { Total Assets }} \times 100
$$

2. Quick ratio :

Quick Rasio $=\frac{\text { Cash Assets }}{\text { Total deposits }} \times 100$

3. Cash Ratio

Cash Ratio $=\longrightarrow 100$

Pinjaman yang harus segera dibayar

\section{Ratio Permodalan}

Rasio ini adalah modal merupakan salah satu faktor yang penting bagi bank. Dalam rangka mengembangkan usaha dan menopang risiko kerugian yang mungkin timbul dari penanaman dana dalam aktiva aktiva produktiv yang mengundang resiko

serta untuk membiayai penanaman dalam aktiva lainnya.

1. Primary Ratio

Equity Capital

Equity Capital $=\longrightarrow$ $\times 100$

Total Assets

2. Capital Ratio

Capital Ratio $=\frac{\text { Equity Capital }}{\text { Total Loans }} \times 100$

\section{Pembahasan}

Teknik analisis data yang digunakan oleh peneliti adalah dengan menggunakan rasio keuangan yaitu rasio profitabilitas, rasio likuditas,dan rasio permodalan. Berikut merupakan hasil analisis yang dilakukan pada PT Bank SULUT GO pada tahun 2015 sampai 2017.

Tabel Hasil Perhitungan Profitabilitas Terhadap Laporan Keuangan PT Bank SULUTGO GO Selama tiga tahun terakhir 2015-2017 (Dalam jutaan rupiah)

\begin{tabular}{lccc}
\hline $\begin{array}{l}\text { Rasio } \\
\text { Profitabilitas }\end{array}$ & 2015 & 2016 & 2017 \\
\hline $\begin{array}{l}\text { Return on } \\
\text { assets (\%) }\end{array}$ & $1 \%$ & $1,5 \%$ & $2 \%$ \\
\hline $\begin{array}{l}\text { Return on } \\
\text { Equity (\%) }\end{array}$ & $13 \%$ & $14 \%$ & $20 \%$ \\
\hline $\begin{array}{l}\text { Net profit } \\
\text { margin (\%) }\end{array}$ & & & \\
\hline $\begin{array}{l}\text { Sumber : Laporan keungan } \\
\text { PT }\end{array}$ & Bank \\
$\begin{array}{l}\text { SULUTGO, 2015-2017 } \\
\text { Berdasarkan Tabel di atas dapat dilihat } \\
\text { bahwa : }\end{array}$
\end{tabular}


Terlihat bahwa Return on Assets di peroleh hasil tahun 2015 sebesar 1\% tahun 2016 sebesar 1,5\% dan tahun 2017 sebesar $2 \%$. Return on asset di nilai dalam keadaan yang baik karena kemampuan aktiva yang diinvestasikan untuk berputas dalam menghasilkan laba yang tinggi.

Terlihat bahwa Return on Equity di peroleh hasil tahun 2015 sebesar 13\% tahun 2016 sebesar 14\% dan tahun 2017 sebesar $20 \%$. Return on equty di nilai dalam keadaan yang baik karena kemampuan aktiva yang diinvestasikan untuk berputas dalam menghasilkan laba yang tinggi.

Terlihat bahwa Net profit Margin di peroleh hasil tahun 2015 sebesar 19\% tahun 2016 sebesar 24\% dan tahun 2017 sebesar $39 \%$. Net profit Margin di nilai dalam keadaan yang baik karena kemampuan aktiva yang diinvestasikan untuk berputas dalam menghasilkan laba yang tinggi.

Tabel 2 Hasil Perhitungan Likuiditas Terhadap Laporan Keuangan PT Bank SULUTGO GO Selama tiga tahun terakhir 2015-2017 (Dalam jutaan rupiah)

\begin{tabular}{lccc}
\hline \multicolumn{1}{c}{ Tahun } & 2015 & 2016 & 2017 \\
\hline LAR & $81 \%$ & $79 \%$ & $68 \%$ \\
\hline $\begin{array}{l}\text { Quick } \\
\text { ratio }\end{array}$ & $129 \%$ & $142 \%$ & $126 \%$ \\
\hline $\begin{array}{l}\text { Cash } \\
\text { Ratio }\end{array}$ & $126 \%$ & $138 \%$ & $124 \%$ \\
\hline
\end{tabular}

Sumber : Laporan keungan PT Bank SULUTGO , 2015-2017

Berdasarkan Tabel di atas dapat dilihat bahwa pada perhitungan LAR, di dapatkan angka LAR pada bank SULUT mengalami penurunan dari $81 \%$ menjadi 68\% selama tahun 2015 sampai 2017. Angka ini meunjukan bahwa bank SULUT memerlukan $81 \%$ dari aset totalnya untuk memberikan kredit pada pihak ketiga,dan mengalami penurunan menjadi $68 \%$ pada tahun 2017. Penurunan LAR ini mengidentikasikan bahwa bank SULUT memerlukan semakin sedikit aset total untuk membiayai kredit yang di berikan. Dengan demikian, jika kita melihat dari sisi LAR pada babk SULUT, likuditas bank SULUT semakin bagus, karena bank SULUT tidak membutuhkan aset yang besar untuk membiayai kredit yang diberikan.

Quick Ratio di peroleh hasil tahun 2015 sebesar 129\% tahun 2016 sebesar 142\% tahun 2017 sebesar 126\% .Quick Ratio selama tahun 2015-2017 mengalami nilai yang kurang baik di sebabkan jika mengacu pada ketentuan BI No. 9/1/PBI/2007 maksimum sebesar 100\%. Hasil perhitungan yang di peroleh menunjukan angka melebihi $100 \%$.

Tahun 2015 diperoleh Cash ratio pada Bank sebesar 126\% Kemudian Pada Tahun 2016 cash rasio pada Bank SULUT GO sebesar 138\% dan tahun 2017 di peroleh cash rasio $124 \%$.Cash rasio dari tahun 2015 sampai 2017 tersebut mengalami peningkatan dan penurunan. 
Peningkatan tersebut disebabkan oleh cash asset yang dimiliki Bank SULUTGO di banding dengan pinjaman yang harus dibayar di muka dan penurunan di sebabkan karena simpanan berjangka lebih besar di banding dengan cash assets. Maka pada ketentuan BI No.91//PBI/2007 yang mewajibkan cash ratio minimum sebesar $75 \%$, semakin tinggi rasio ini, maka semakin baik kinerja suatu bank. Jadi bank SULUT dalam kategori bank yang berkinerja baik karena hasil yang di peroleh menunjukan angka yang di atas ketentuan BI.

Tabel 3. Hasil Perhitungan Permodalan Terhadap Laporan Keuangan PT Bank SULUTGO GO Selama tiga tahun terakhir 2015-2017 (Dalam jutaan rupiah)

\begin{tabular}{lccc}
\hline Tahun & 2015 & 2016 & 2017 \\
\hline $\begin{array}{l}\text { Primary } \\
\text { Ratio }\end{array}$ & $8,95 \%$ & $9,98 \%$ & $8,28 \%$ \\
\hline $\begin{array}{l}\text { Capital } \\
\text { Ratio }\end{array}$ & $11,004 \%$ & $12,674 \%$ & 12, \\
\hline
\end{tabular}

Sumber : Laporan keungan PT Bank SULUTGO , 2015-2017

Berdasarkan Tabel di atas dapat dilihat bahwa :

Perhitungan prima ratio selama 3 tahun yaitu pada tahun 2015 sampai dengan 2017 PT Bank SULUT GO memperoleh nilai rasio yang mengalami kenaikan dan penurunan. Nilai primary ratio pada tahun 2015 yaitu sebesar 8,95\% menunjukan bahwa setiap Rp 1,00 asset dijamin dengan RP 0,895 modal bank. Pada tahun 2016
LAR pada primary ratio sebesar $9,98 \%$ tahun ini LAR pada bank mengalami kenaikan di karenakan bahwa setiao Rp 1,00 asset di jamin dengan oleh Rp 0,998 modal bank. Kemudian pada tahun 2017 LAR pada bank mengalami penurunan dari tahun sebelumnya yaitu sebesar $8,28 \%$ bahwa menunjukan setiap $\mathrm{Rp} 1,00$ aset dijamin dengan Rp 0,082 modal bank. Jadi dapat di simpulkan bahwa primary ratio dari tahun 2015 sampai 2017 meskipun mengalami kenaikan dan penurunan namun primary rasio pada bank SULUT masih terbilang baik karena memenuhi standar BI - Standar BI minimun 3\% - 6\% primary ratio yang semakin tinggi maka semakin baik tingkat rasio permodalan.

Capital ratio pada tahun 2015 sebesar $11,004 \%$ artinya kemampuan permodalan bank dalam menutupi kemungkinan kegagalan yang ada dalam proses permodalan kredit adalah 11,004\% . Di tahun di 2016 capital ratio 12,674\% di banding dengan tahun 2015 11,004\% berarti pada tahun 2016 capital ratio mengalami kenaikan dari tahun sebelumnya. Naiknya rasio ini pada tahun 2016 dari rasio sebelumnya artinya kemampuan permodalan meningkat dalam menutupi kemungkinan kegagalan yang ada dalam proses permodalan kredit. Kemudian pada tahun 2017 capital ratio sebesar $12,139 \%$ yang artinya mengalami 
penurunan dari tahun sebelumnya di karenakan kemampuan permodalan menurun dari tahun sebelumnya. Jadi pada capital ratio pada tahun 2015 sampai 2017 meskipun mengalami kenaikan dan penurunan. Namun capital rasio pada bank SULUT GO masih bisa di bilang baik karena memenuhi standar BI. Standar minimum BI yaitu $10 \%-20 \%$ primary ratio yang semakin tinggi maka akan semakin baik tingkat solvabilitas.

\section{Kesimpulan}

Berdasarkan hasil analisis yang telah diuraikan sebelumnya,maka dapat ditarik kesimpulan sebagai berikut :

Berdasarkan analisis rasio Profitabilitas pada tahun 2015-2017 Return on Assets PT Bank SULUTGO dinilai dalam keadaan yang baik karena kemampuan aktiva yang diinvestasikan untuk berputar dalam menghasilkan laba sangat tinggi. Sedangkan pada tahun 2015 - 2017 Return on Equity PT Bank SULUT GO di nilai dalam keadaan yang baik karena kemampuan ekuitas/modal yang di gunakan untuk menghasilkan laba sangat tinggi. Kemudian Pada tahun 2015 - 2017 PT Bank SULUTGO Net profit Margin di nilai dalam keadaan yang baik juga karena kemampuan aktiva yang diinvestasikan untuk berputar dalam menghasilkan laba yang tinggi.
Berdasarkan analisi rasio Likuditas PT Bank SULUT GO pada tahun 2015 sampai 2017 LAR di nilai baik karena bank SULUT kategori bank yang berkinerja baik karena hasil perhitungan yang di peroleh menunjukan angka yang di atas standar dari ketentuan BI. Quick Ratio di peroleh hasil tahun 2015 sebesar 129\% tahun 2016 sebesar 142\% tahun 2017 sebesar 126\% .Quick Ratio selama tahun 2015-2017 mengalami nilai yang kurang baik di sebabkan jika mengacu pada ketentuan BI No. 9/1/PBI/2007 maksimum sebesar 100\% - Hasil perhitungan yang di peroleh menunjukan angka melebihi 100. Kemudian Tahun 2015 diperoleh Cash ratio pada Bank sebesar 126\% Kemudian Pada Tahun 2016 cash rasio pada Bank SULUT GO sebesar 138\% dan tahun 2017 di peroleh cash rasio $124 \%$

Berdasarkan analisis rasio permodalan PT. Bank SULUT GO primary ratio dari tahun 2015 - 2017 dapat di katakan baik meskipun mengalami kenaikan dan penurunan namun primary rasio pada bank SULUT masih terbilang baik karena memenuhi standar BI. Kemudian capital ratio dari tahun 2015 2017 juga dapat dikatakan baik karena meskipun mengalami kenaikan dan penurunan namun primary rasio pada bank SULUT masih terbilang baik karena memenuhi standar BI. 


\section{Saran}

Mengacu pada kesimpulan di atas, maka dapat diajukan beberapa saran sebagai berikut :

Saran rasio profitabilitas ialah. Profitabilitas pada 2015 sampai 2017 menghasilkan laba yang tinggi. Maka peneliti mengharapkan perbankan selalu berusaha meningkatkan kinerja keuangan bank SULUT agar kemampuan aktivitas dan ekuitas yang di investasikan untuk berputar jadi lebih baik. Agar supaya pada tahun tahun berikutnya tidak mengalami penurunan pada laba bersih, tetapi bisa terjadi peningkatan laba bersih pada tahun tahun berikutnya.

Saran rasio likuiditas adalah. Rasio ini meskipun mengalami kenaikan dan penuruna nilai pada rasio rasio yang di analisis. Tetapi meskipun begitu rasio likuiditas termaksud pada nilai yang baik karena memenuhi standar yang di berikan kententuan BI. Sarannya ialah bagi bank SULUT mengelolah likuiditas sedapat mungkin dilakukan dengan tindakan manajemen likuiditas, dengan memperhatikan segala kemungkinan yang ada yang menyebabkan nilai yang menurun pada nilai bank dan juga kinerja keuangannya agar kedepannya jadi jauh lebih baik dan tetap memenuhi standar BI.

Dilihat dari analisis rasio permodalan, menunjukan bahwa rasio keuangan PT
Bank SULUT pada tahun 2015 sampai tahun 2017 meskipun mengalami kenaikan dan penurunan. Maka saran untuk rasio rasio yang sempat mengalami menurunan, perbankan di harapkan dapat lebih memperhatikan faktor faktor yang menjadi penurunan ini. Agar dapat menjadi bahan evaluasi di tahun tahun selanjutnya dan supaya tetap memenuhi standar BI.

\section{Daftar Pustaka}

Galagher. (2011). Rasio Profotability. Jakarta: Journal Works Press.

Harahap. (2010). Analisis Krisis atas Laporan Keuangan. Jakarta: PT.Raja Grfindo Persada.

Muljono. (2011). Analisis Laporan Keuangan untuk Perbankan. Jakarta.

Sutrisno. (2012). Jakarta: Mengkur Seberapa Besar Tingkat Keuntuangn yang di Peroleh Perusahaan, Journal of Works Press. 